\title{
Preparation of ZnO Film on p-Si and I-V Characteristics of p-Si/n-ZnO
}

\author{
Shampa Mondal, Kalyani Prasad Kanta, Partha Mitra*
}

Department of Physics, The University of Burdwan, Burdwan, 713104, India

Received: August 28, 2011; Revised: August 19, 2012

\begin{abstract}
Zinc oxide $(\mathrm{ZnO})$ thin films were deposited on p-silicon ( $\mathrm{Si}$ ) substrate from ammonium zincate bath following a chemical dipping technique called SILAR. Films in the thickness range 0.5-4.5 $\mu \mathrm{m}$ could be prepared by varying the number of dipping for a fixed concentration $(0.125 \mathrm{M})$ of zincate bath and fixed $\mathrm{pH}$ (11.00-11.10). Higher values of dipping produced nonadherent and poor quality films. Structural characterization by X-ray diffraction (XRD) indicates the formation of polycrystalline single phase $\mathrm{ZnO}$ with strong c-axis orientation. The structural characteristics of the films were found to be a sensitive function of film thickness. The degree of orientation was found to be a function of film thickness and a maximum was found at around $2.2 \mu \mathrm{m}$. Scanning electron microscopy (SEM) reveals the formation of sub-micrometer crystallites on silicon substrate. The coverage of crystallites (grains) on substrate surface increases with number of dipping. Dense film containing grains distributed throughout the surface is obtained at large thicknesses. The ohmic nature of silver $(\mathrm{Ag})$ on $\mathrm{ZnO}$ and Aluminum (Al) on p-Si was confirmed by I-V measurements. I-V characteristic of the $\mathrm{p}-\mathrm{Si} / \mathrm{n}-\mathrm{ZnO}$ heterojunction was studied and rectification was observed. The maximum value of forward to reverse current ratio was $\sim 15$ at $3.0 \mathrm{~V}$.
\end{abstract}

Keywords: chemical dipping, $p$-Si/n-ZnO, orientation, heterojunction

\section{Introduction}

Zinc oxide $(\mathrm{ZnO})$ is a wide-gap semiconductor with a band gap of $3.36 \mathrm{eV}$ at room temperature and has been extensively studied because of its potential applications in various fields, such as gas sensors, solar cells, photodetectors, light emitting diodes, laser systems, etc. It is well known that undoped $\mathrm{ZnO}$ films generally indicate n-type conduction. $\mathrm{ZnO}$ films have been epitaxially grown on sapphire or $\mathrm{Si}$ substrates by several physical and chemical methods such as molecular beam epitaxy (MBE), sputtering, atomic layer deposition, metal oxide chemical vapor deposition (MOCVD) and sol-gel ${ }^{1-5}$. Silicon is suitable for the integration of optoelectronic devices. It is also cheaper and easier to cleave silicon compared to sapphire. Thus efforts have been mostly directed to grow $\mathrm{n}-\mathrm{ZnO}$ thin films on $\mathrm{p}$-Si substrate. Heterojunction of $\mathrm{n}-\mathrm{ZnO} / \mathrm{p}-\mathrm{Si}$ have potential applications in the visible and ultraviolet photodiodes, gas sensors among many others ${ }^{4-6}$. Fast switching of $n-\mathrm{ZnO} / \mathrm{p}-\mathrm{Si}$ diode without any reverse recovery delay has been reported by Choi et al. ${ }^{1}$. Such reverse recovery delay is often observed in Si p-n diode. Zeng et al. ${ }^{7}$ reported higher ability of $\mathrm{n}-\mathrm{ZnO} / \mathrm{p}-\mathrm{Si}$ heterojunction to produce photoelectrons than one of Si solar cell. The photocurrent property was measured and $20 \%$ greater saturation photocurrent of $n-\mathrm{ZnO} / \mathrm{p}-\mathrm{Si}$ compared to $\mathrm{Si}$ solar cell was reported in their work. In this paper, $\mathrm{n}-\mathrm{ZnO}$ films were grown on $\mathrm{p}-\mathrm{Si}$ substrates by successive ion layer adsorption and reaction (SILAR). The structural properties of $\mathrm{ZnO}$ films deposited on silicon substrate were evaluated. The heterojunction properties were also investigated by means of $I-V$ measurements.

*e-mail: mitrapartha1@ rediffmail.com
The conventional physical techniques (such as MBE or different forms sputtering) generally produce good quality transparent films. However they are very expensive and are difficult to carry out in the industrial level. Chemical deposition techniques, on the other hand, are relatively low cost processes and can be easily scaled up for industrial applications. During the last few decades, chemical techniques have come out to be a good alternative for material preparation in thin film form. The chemical deposition of oxide thin films from an aqueous solution is a very promising method particularly because of its simplicity and economy. The different chemical methods generally used to grow $\mathrm{ZnO}$ thin films are sol-gel, spray pyrolysis, electroless deposition and chemical bath deposition (CBD). One of the less used and less studied chemical techniques is successive ionic layer adsorption and reaction (SILAR). SILAR is often termed as modified chemical bath deposition. In CBD, deposition of thin films occurs due to substrate maintained in contact with dilute chemical bath ${ }^{8}$. The film formation on substrate takes place when ionic product exceeds solubility product. In SILAR, thin films are obtained by alternate dipping of the substrate into separately placed cationic and anionic precursors for reaction at chosen temperatures. The technique was given the name SILAR by Nicolau et al. ${ }^{9}$ since it involves adsorption of a layer of complex ion on the substrate followed by reaction of the adsorbed ion layer.

The technique of SILAR has been proved to be useful for deposition of thin films of metal sulphides (chalcogenides) ${ }^{8}$. Since first reported by Ristov et al. ${ }^{10}$, not much effort has been made to deposit oxide thin films by this technique 
and has remained a relatively less investigated method. Earlier we reported the preparation of $\mathrm{ZnO}$ thin films by this technique from sodium zincate or ammonium bath ${ }^{11-13}$. Since SILAR has the advantage that films can be deposited on any kind of substrate, the objective of the present work is to promote interest in this method as applied to fabrication of $\mathrm{ZnO}$ thin film on $\mathrm{p}$-Si substrate. The microstructural features of the films were studied using X-ray diffractometer (XRD) and scanning electron microscope (SEM). Characterization of the $\mathrm{n}-\mathrm{ZnO} / \mathrm{p}-\mathrm{Si}$ heterojunction so formed was carried out by current-voltage $(I-V)$ measurements.

\section{Experimental}

The details of zinc oxide film deposition on microscope glass substrate following chemical dipping from sodium zincate or ammonium zincate bath have been reported elsewhere ${ }^{11-13}$. In brief, the process involves multiple dipping of the substrate in the zincate bath maintained at room temperature and hot water bath maintained near boiling point. The zincate complex was prepared by adding sodium hydroxide $(\mathrm{NaOH})$ or ammonium hydroxide $\left(\mathrm{NH}_{4} \mathrm{OH}\right)$ in a solution of zinc salt (zinc sulphate or zinc acetate). The reaction leading to the formation of $\mathrm{ZnO}$ on the substrate for ammonium zincate bath is as follows:

$$
\left(\mathrm{NH}_{4}\right)_{2} \mathrm{ZnO}_{2}+\mathrm{H}_{2} \mathrm{O}=\mathrm{ZnO}+2 \mathrm{NH}_{4} \mathrm{OH}
$$

Similarly the reaction leading to $\mathrm{ZnO}$ formation for sodium zincate bath is as follows:

$$
\mathrm{Na}_{2} \mathrm{ZnO}_{2}+\mathrm{H}_{2} \mathrm{O}=\mathrm{ZnO}+2 \mathrm{NaOH}
$$

Dipping of the substrate in zincate bath results in a thin layer of the zincate solution on the substrate. Subsequent dipping of the substrate in hot water leads to breaking down of the complex and formation of $\mathrm{ZnO}$. For the present work, ammonium zincate bath was selected. Although the growth rate from sodium zincate bath ( 0.20 per dipping per mole) is always on the higher side compared to that from ammonium zincate bath ( 0.16 per dipping per mole), there is incorporation of sodium in films prepared from sodium zincate bath. Figure 1 shows the energy dispersive X-ray (EDX) pattern of a $\sim 5.0 \mu \mathrm{m}$ thick $\mathrm{ZnO}$ film obtained from sodium zincate bath on silicon substrate. The peak due to sodium merges with one peak of zinc. Sodium was found to be present in approximately 0.7 element $\%$. Trace amount of $\mathrm{Ca}(\sim 0.11$ atomic $\%)$ and $\mathrm{Cl}(0.06$ atomic \%) was also detected in the film.

The silicon (p-Si) substrate used for deposition was first dipped in the zincate bath and then in hot water (maintained near boiling point). The dipping time in each bath was 2 seconds. The film thickness was built up by increasing the number of dipping cycles. A part of $\mathrm{ZnO}$ so formed is deposited onto the substrate as a strongly adherent film and another part of it formed a precipitate in the hot water bath. The silicon substrate [p-Si (100)] used for deposition was etched in dilute hydrofluoric acid (HF) to remove native oxide. It was then thoroughly washed with distilled water followed by cleaning with $1: 1$ by volume methanol-hydrochloric acid mixture and finally followed by deionized water cleaning. Two such substrates were pressed back-to-back and used for deposition. This allows only one surface of a substrate to be coated with the film. The deposited $\mathrm{ZnO}$ films were subsequently annealed in air at $200{ }^{\circ} \mathrm{C}$.

The film thickness was determined gravimetrically by measuring the change in weight of the substrate due to film deposition, the area of deposition and using the known density of $\mathrm{ZnO}$. XRD with $\mathrm{CuK} \alpha$ radiation $(\lambda=1.5418 \AA$ ) was used for structural characterization and phase identification of the deposited $\mathrm{ZnO}$ films. SEM was used to illustrate the formation of crystallites on the film surface. The ohmic nature of silver $(\mathrm{Ag})$ contact on $\mathrm{ZnO}$ was verified by I-V measurements. Similarly ohmic nature of aluminium (Al) on p-Si was verified. The I-V characteristics of the $\mathrm{n}-\mathrm{ZnO} / \mathrm{p}-\mathrm{Si}$ heterojunction was measured in a Solatron meter (Schlumberger S1 1286).

\section{Results and Discussions}

\subsection{Film growth rate vs. number of dipping}

Film growth was done for a fixed concentration of ammonium zincate bath $(0.125 \mathrm{M})$ and fixed $\mathrm{pH}(11.0-11.1)$ of the bath. These values were found to be optimum ${ }^{12}$ for getting good quality adherent films. Erratic and poor quality films results for concentrations higher than $0.15 \mathrm{M}$. The $\mathrm{pH}$ measurements were done in a Systronics $\mathrm{pH}$ meter (Model 335). For $\mathrm{pH}$ values greater than 11.1, the growth rate decreases abruptly and for $\mathrm{pH}$ less than 11.0 , only non-adherent powder like precipitate appears. The bath solution tends to lose stability with decreasing $\mathrm{pH}$ and precipitates of zinc hydroxide appear in the baths on standing.

Figure 2 shows the variation of $\mathrm{ZnO}$ film thickness with number of dipping (25-200 dipping cycle) for $0.1 \mathrm{M}$ ammonium zincate bath. The growth rate was calculated as $\mu \mathrm{m}$ per dipping per mole and it was $\sim 0.18$. The growth rate is slightly on the higher side compared to that on glass $(\sim 0.16)^{[13]}$. The film thickness was measured gravimetrically ${ }^{14}$ by taking the theoretical density of the material ( $\rho=5.6 \mathrm{gm} . \mathrm{cm}^{-3}$ for $\left.\mathrm{ZnO}\right)$. Thus, if $W_{1}$ and $W_{2}$ be

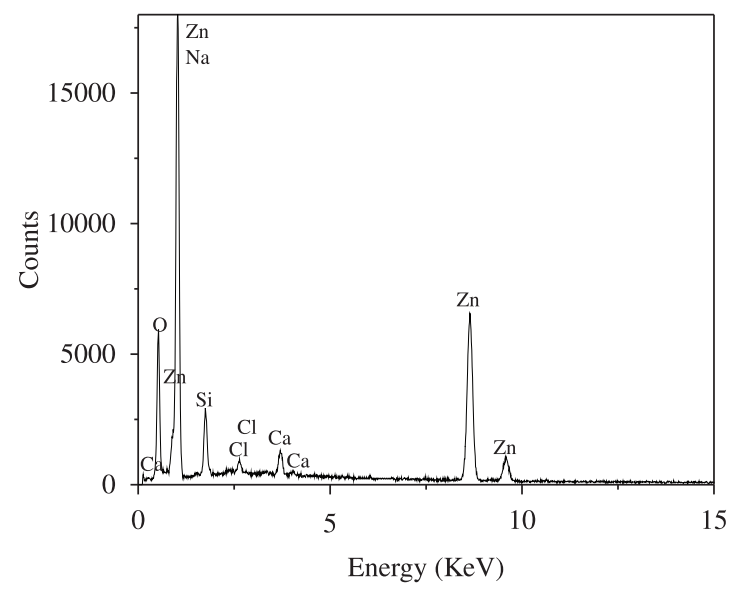

Figure 1. $\mathrm{EDX}$ of $\sim 5 \mu \mathrm{m}$ thick $\mathrm{ZnO}$ film prepared from sodium zincate bath. 
the weights of the substrate before and after film deposition in $\mathrm{gm} . A$ is the area of film deposition in $\mathrm{cm}^{2}$ and $\rho$ be the theoretical density of $\mathrm{ZnO}$; then the film thickness was evaluated as follows:

$d=\frac{\left(W_{2}-W_{1}\right)}{A \rho} \times 10^{-4} \mu \mathrm{m}$

The weighing of the substrate before and after deposition was made in an electronic balance. The area of film deposition was evaluated by measuring the length and breadth of the substrate surface using slide callipers. Rectangular substrate $(1 \mathrm{~cm} \times 1 \mathrm{~cm})$ was used for film deposition. Thus unit area of the substrate surface was used for coating films.

The gravimetry method of film thickness determination has some limitations because of non-uniformity, porosity and edge tapering effects in the chemically deposited films with porous microstructure. The actual film density is lower than the theoretical density and the thickness measured using theoretical density is less than the actual thickness ${ }^{12}$. However, this error does not affect the comparative data of measured film thickness. Cross sectional SEM measurement shows that an approximate error of $20 \%$ is involved in thickness values measured gravimetrically ${ }^{12}$.

\subsection{Structural characterization}

Figure 3 shows the X-ray diffraction pattern of a $\sim 2.2 \mu \mathrm{m}$ thick $\mathrm{ZnO}$ film deposited on silicon substrate from ammonium zincate bath. The film was annealed at $150{ }^{\circ} \mathrm{C}$ in air prior to structural characterization. It is seen from Figure 3 that (002) is the strongest line, indicating strong preferred c-axis orientation. The variation of degree of c-axis orientation with film thickness is shown in the Figure 4. The intensity ration $[I(002) / I(101)]$ is plotted against film thickness [XRD patterns of films of different thicknesses are not shown for brevity]. Here $I(002)$ and $I(101)$ are the intensities of (002) and (101) diffraction lines. The reason for selecting $\mathrm{ZnO}$ (101) line is due to the fact that this is the strongest XRD line for standard zinc oxide powder with no preferred orientation. The value of $[I(002) / I(101)]$ is 0.56 for $\mathrm{ZnO}$ powder ${ }^{15}$.

It can also be seen from the Figure 4 that initially the degree of c-axis orientation increases with film thickness upto $2.2 \mu \mathrm{m}$ and subsequently, the degree of c-axis orientation decreases for thicker films. The onset of loss of c-axis orientation can be attributed to the interruption of preferred growth. A change of preferred orientation around $0.55 \mu \mathrm{m}$ was observed for rf sputtered films ${ }^{16}$ deposited on glass. It was found that the films were well-oriented normal to the substrate upto $0.55 \mu \mathrm{m}$, but with increasing film thickness, the intensity of the (002) diffraction peak was reduced. The preferred orientation of the films changed from (002) to a more or less random orientation with increasing thickness.

The phenomenon was explained in terms of surface free energy. The most densely packed planes have the lowest surface energy and preferred orientation ${ }^{15}$. Thus the driving force of the texture development is believed to be the surface energy minimization, because (002) is the most densely packed plane in $\mathrm{ZnO}$ with wurtzite structure. As the film becomes thicker, the driving force for preferred orientation is reduced due to lowering of surface energy together with increasing strain energy ${ }^{17-18}$. The preferred orientation of the films is governed by the total system energy, which is the summation of the strain and surface energies ${ }^{16-18}$. As explained in some literature ${ }^{16-17}$, at the initial stage of film growth, surface energy plays the dominant role, but at a later stage, the growth process is primarily controlled by variation of strain energy.

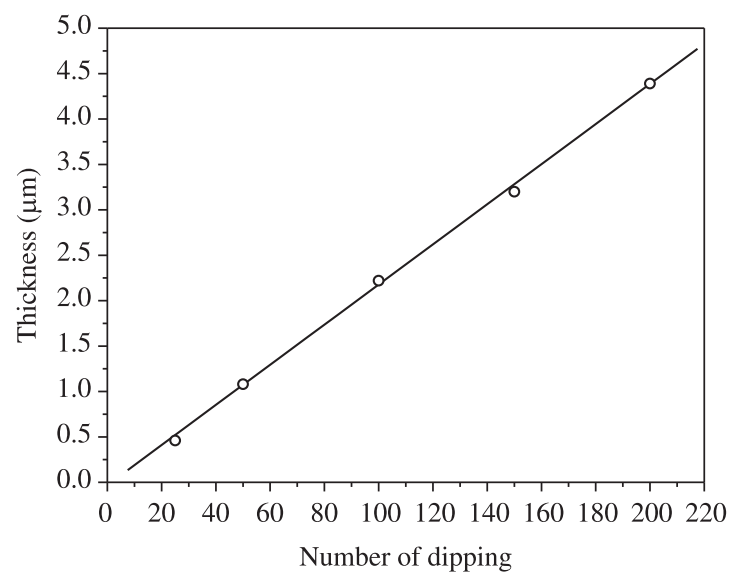

Figure 2. Variation of film thickness with number of dipping in ammonium zincate bath.

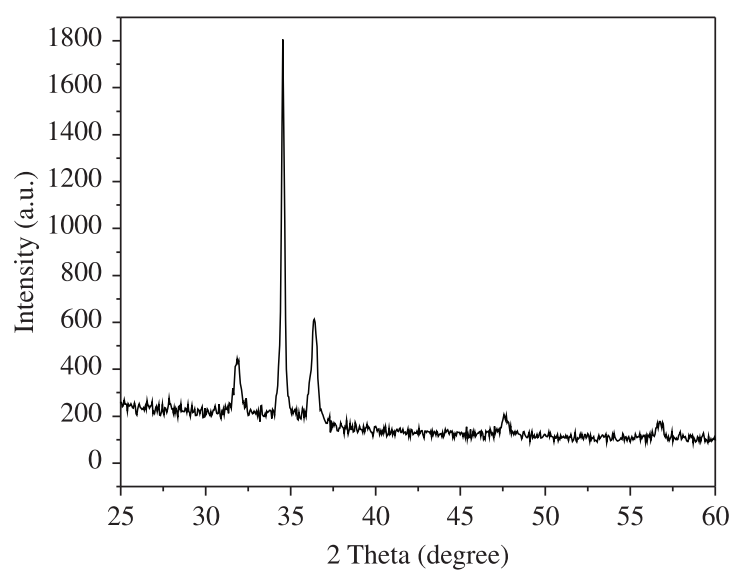

Figure 3. XRD of $\sim 2.2 \mu \mathrm{m}$ thick $\mathrm{ZnO}$ film on $\mathrm{p}-\mathrm{Si}$.

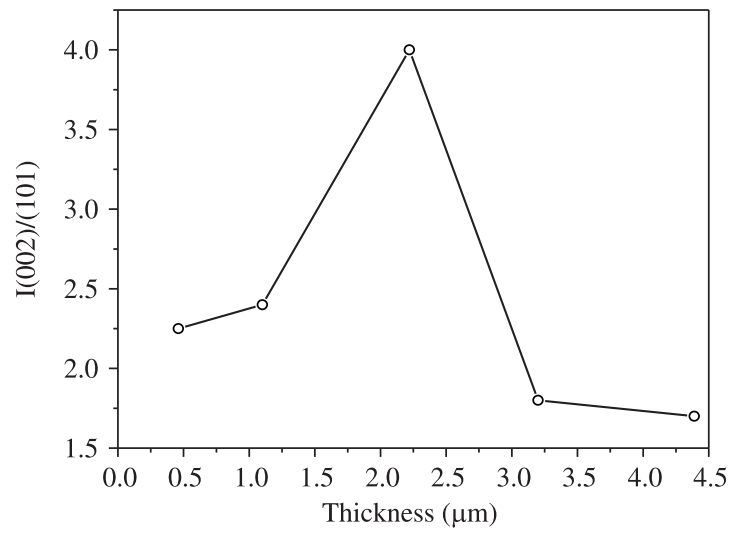

Figure 4. Variation of c-axis orientation with thickness. 
Scanning electron microscopy was used to examine the formation of crystallites on the film surface. The photographs of films under varying thickness are shown in Figures 5-7. Figures represents photographs for $0.46 \mu \mathrm{m}$ thick, $1.1 \mu \mathrm{m}$ thick and $3.2 \mu \mathrm{m}$ thick $\mathrm{ZnO}$ film respectively on silicon substrate, which corresponds to 25, 50 and 150 dipping films respectively. The photographs clearly demonstrate the effect of increased number of dipping (i.e. increased thickness) on surface morphology. Significant differences were observed in the three images. All the pictures reveal

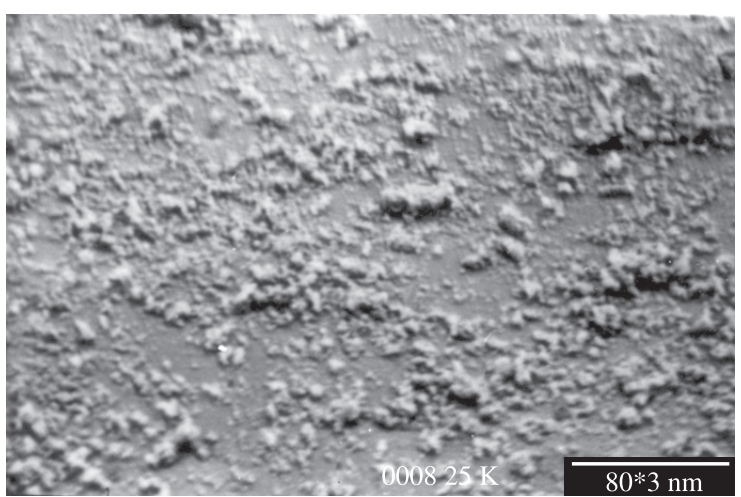

Figure 5. SEM micrograph of $\sim 0.46 \mu \mathrm{m}$ thick $\mathrm{ZnO}$ film on $\mathrm{p}-\mathrm{Si}$ (25 dipping).

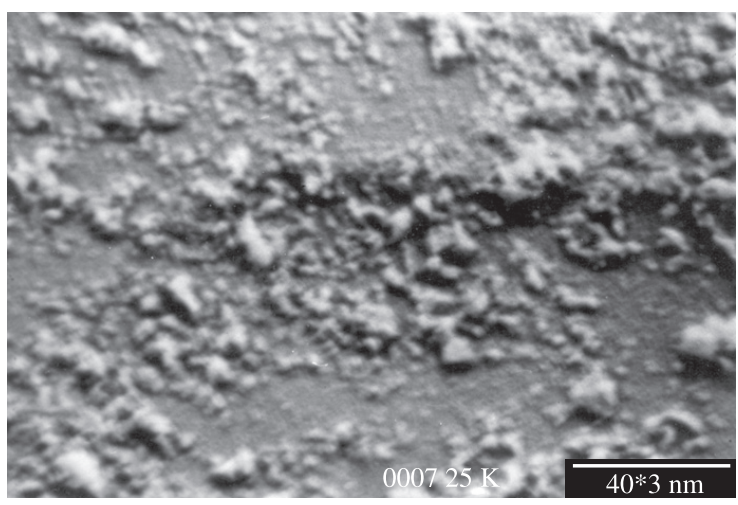

Figure 6. SEM micrograph of $\sim 1.1 \mu \mathrm{m}$ thick $\mathrm{ZnO}$ film on $\mathrm{p}-\mathrm{Si}$ (50 dipping).

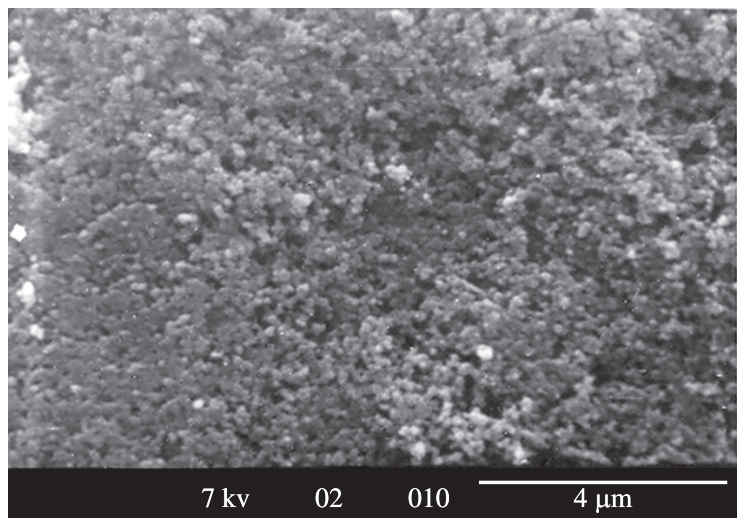

Figure 7. SEM micrograph of $\sim 2.2 \mu \mathrm{m}$ thick $\mathrm{ZnO}$ film on $\mathrm{p}-\mathrm{Si}$ (100 dipping). the formation of polycrystalline (sub-micrometer) nature of the films. It appears that at the initial stage of deposition, a large amount of small grains (crystallites) are distributed at random sites The size and abundance of these single crystallites seems to depend on number of dipping. The surface morphology is also relatively rough at this stage with structure characteristics of a collection of crystallites which have grown to different sizes. For 150 dipping, the coverage seems to be complete (clear grains cover almost entire surface of the silicon substrate). Also the surface of the film is relatively smooth. In other words dense film grew with increasing number of dipping which are well adhered to the substrate. Although no cracks or holes could be found, some holes indicating porosity is present. It also appears from the micrographs that geometry of the grains grown at higher number of dipping are spherical, while those at lower number of dipping are not so. This may be associated with release of surface energy for higher thicknesses as has been mentioned earlier. However, further investigation is required to explain the entire phenomenon. Agglomeration of small crystallites seems to be present in certain regions of the film surface. This is possible since the method of preparation allows stacking and agglomeration of initial single particles.

\subsection{I-V characteristics}

The heterojunction characteristic of $\mathrm{n}-\mathrm{ZnO} / \mathrm{p}-\mathrm{Si}$ was measured by studying the I-V characteristics. Prior to this, room temperature curing $\mathrm{Ag}$ paste was applied on $\mathrm{ZnO}$. The I-Vcharacteristic was studied by measuring the voltage with varying current at room temperature $(\mathrm{T} \sim 30 \mathrm{C})$ in order to see whether the film possesses ohmic or rectifying contacts. The current-voltage (I-V) plot of $\mathrm{Ag} / \mathrm{n}-\mathrm{ZnO}$ contact is shown in Figure 8. The linear relationship of the characteristics reveals that the contact has ohmic character. Similarly Aluminum dots were evaporated on silicon in a vacuum coating unit. It was cured in nitrogen flow. Figure 9 shows the current-voltage characteristics of $\mathrm{Al} / \mathrm{p}-\mathrm{Si}$. The linear nature of the characteristics confirms the ohmic nature of the contact.

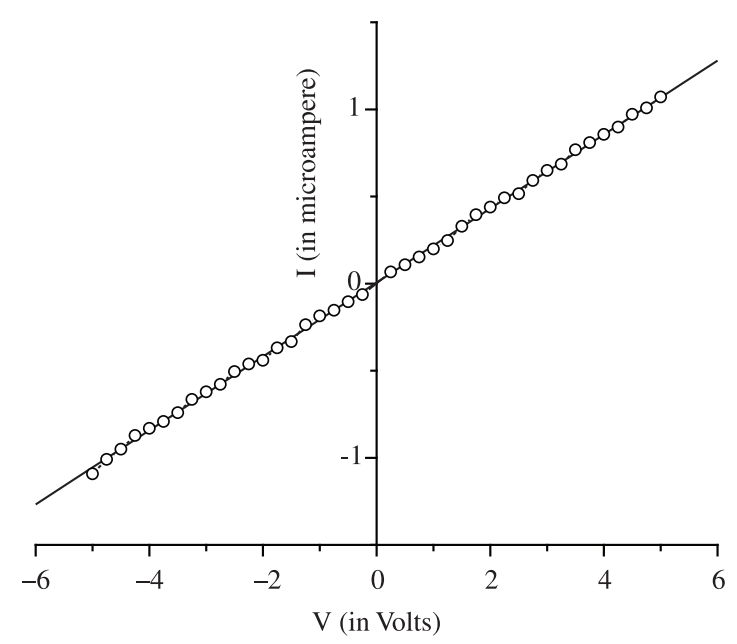

Figure 8. I-V characteristics of Ag- $\mathrm{ZnO}$. 
Figure 10 shows the schematic structure of an n- $\mathrm{ZnO} / \mathrm{p}-\mathrm{Si}$ heterojunction. Figure 11 shows the I-V characteristics of $\mathrm{n}-\mathrm{ZnO} / \mathrm{p}-\mathrm{Si}$ heterostructure at room temperature. The reverse current increases linearly with the increase of the reverse bias voltage which can be explained by the generation current in the depletion region ${ }^{4}$. The forward current increases nonlinearly

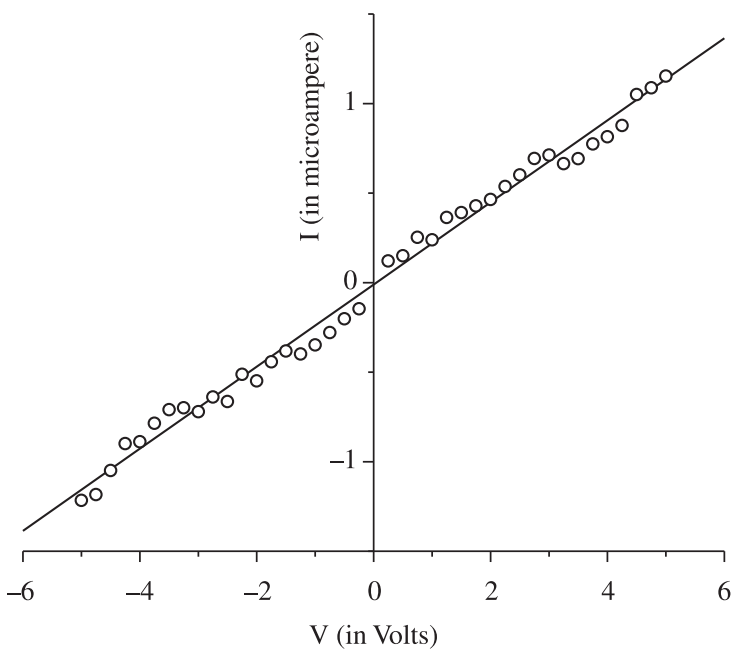

Figure 9. I-V characteristics of Al-Si.

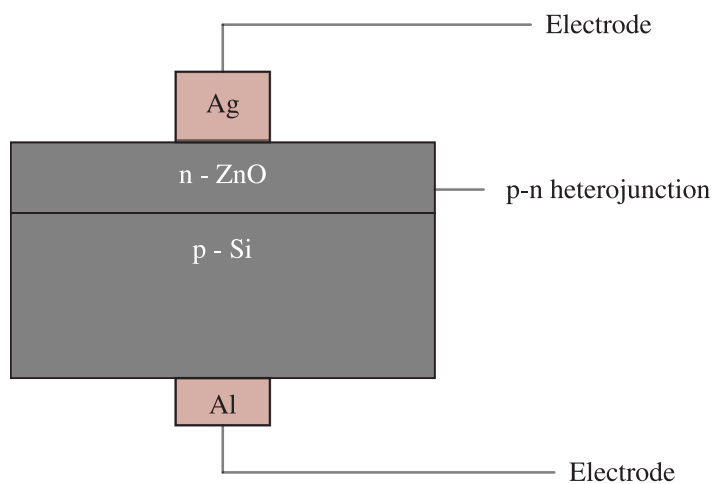

Figure 10. The schematic diagramme of $\mathrm{n}-\mathrm{ZnO} / \mathrm{p}-\mathrm{Si}$ heterojunction.

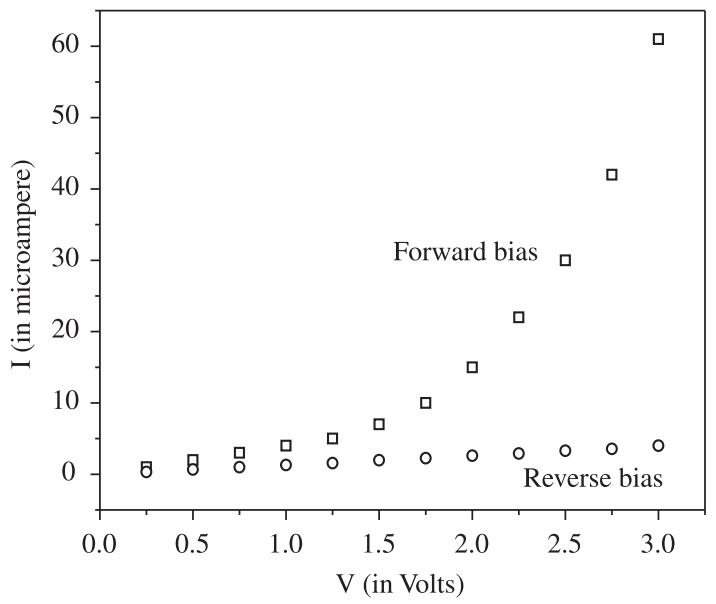

Figure 11. I-V characteristics of $\mathrm{n}-\mathrm{ZnO} / \mathrm{p}-\mathrm{Si}$. with forward bias voltage. Thus the junction was found to be rectifying and the turn-on voltage is about $1.5 \mathrm{~V}$. The maximum forward-to-reverse current ratio was found to be about 15 . This is on the lower side of that normally reported ${ }^{6,19}$. While Basu et al. ${ }^{6}$ have reported a forward to reverse current ratio of 80 at $1 \mathrm{~V}$; Ajimsha et al. ${ }^{19}$ reported a value of 1000 at $5 \mathrm{~V}$ for $\mathrm{n}-\mathrm{ZnO} / \mathrm{p}-\mathrm{Si}$ heterojunctions. Basu et al. ${ }^{6}$ deposited $\mathrm{ZnO}$ films on $\mathrm{p}$-Si substrate by chemical vapor deposition (CVD) technique and Ajimsha et al. ${ }^{19}$ prepared $\mathrm{ZnO}$ films by pulsed LASER deposition technique. Mridha et al. ${ }^{5}$ reported an extremely high value of forward to reverse current ratio of 5700 at $5 \mathrm{~V}$ for sol-gel fabricated films on $\mathrm{p}$-Si. The value of $\sim 15$ obtained for the present case is possibly due to very high resistivity of SILAR deposited films ${ }^{12}$ compared to other technique. The high resistivity of the chemically deposited films compared to those obtained by other methods is due to low donor defect density and presence of a large number of chemisorbed oxygen species which are incorporated in the grains and at the surface of such films during film preparation. This is expected since the deposition is performed in ambient air, large number of oxygen molecules are chemisorbed at the grain boundaries and on the surface ${ }^{12}$.

The trapping of conduction electrons to form negatively charged oxygen species $\left(\mathrm{O}_{2}^{-}, \mathrm{O}^{-}\right.$etc. $)$is considered as the process of chemisorption. The presence of such chemisorbed species thus renders high resistivity to the oxide surface. These negatively charged chemisorbed species acts as reaction centers for reducing gas molecules. When a reducing gases comes in contact with the oxide surface, the reaction between gases molecules and the negatively charged oxygen species results in the release of the trapped electrons. The electrons goes back to the conduction band and results in a decrease in resistance. On removal of the gas, the electrons are again trapped and the resistance increases. Thus such high resistive films containing enhanced density of chemisorbed species are particularly suitable for resistive mode gas sensor applications.

\section{Conclusions}

An analysis of the results presented here indicates that $\mathrm{n}-\mathrm{ZnO}$ thin films can be successfully grown on $\mathrm{p}-\mathrm{Si}$ substrates by low temperature SILAR technique. The structural properties of $\mathrm{ZnO}$ films were investigated using $\mathrm{X}$-ray diffraction. The films have high preferred $c$-axis orientation which is thickness dependent. Highest preferred orientation is observed for $\sim 2.2 \mu \mathrm{m}$ thick film (which corresponds to 100 dipping). SEM micrograph reveals that at the initial stage of deposition, a large amount of small grains are distributed at random sites. Agglomeration of small crystallites is observed in certain regions of the film surface. Relatively smooth and homogeneous film covering more or less the entire surface is observed for large thickness. Current-voltage (I-V) characteristics of $\mathrm{n}-\mathrm{ZnO} / \mathrm{p}-\mathrm{Si}$ heterojunction exhibit nonlinear and rectifying characteristics with maximum forward to reverse ratio of $\sim 15$ at $3.0 \mathrm{~V}$. The low value of forward to current ratio is due to high resistivity of SILAR deposited films. Such high resistive films giving rise to heterostructures with low forward to reverse current ration may be useful for the detection of reducing gases in resistive mode gas sensors. 


\section{References}

1. Choi Y, Lee K, Park CH, Lee KH, Nam J, M Sung MM et al. High current fast switching $\mathrm{n}-\mathrm{ZnO} / \mathrm{p}-\mathrm{Si}$ diode. Journal of Physics D: Applied Physics. 2012; 43:345101-5. http://dx.doi. org/10.1088/0022-3727/43/34/345101

2. Jing MA, Xin JK, Cheng LB, Fei F, Hui X, Chou ZC et al. Rectifying and Photovoltage properties of $\mathrm{ZnO}: \mathrm{Al} / \mathrm{p}-\mathrm{Si}$ heterojunction. Chinese Physics Letter. 2010; 27:1-4. http:// dx.doi.org/10.1088/0256-307X/27/10/107304

3. Skriniarova J, Kovac J, Hasko D, Vincze A, Jakabovic J, Janos $\mathrm{L}$ et al. Structural, electrical and optical properties of $\mathrm{ZnO} / \mathrm{Si}$ structures prepared by sputtering or pulsed laser deposition. Journal of Physics: Conference Series. 2008; 100:1-4. http:// dx.doi.org/10.1088/1742-6596/100/4/042031

4. Zhang Y, Guotong D, Zhang B, Cui Y, Zhu H and Chang Y. Properties of $\mathrm{ZnO}$ thin films grown on $\mathrm{Si}$ substrates by MOCVD and $\mathrm{ZnO} / \mathrm{Si}$ heterojunctions. Semiconductor Science and Technology. 2005; 20:1132-1135. http://dx.doi. org/10.1088/0268-1242/20/11/006

5. Mridha S, Dutta M and Basak D. Photoresponse of n-ZnO/p-Si heterojunction towards ultraviolet/visible lights: thickness dependent behavior. Journal of Materials Science: Materials in Electronics. 2008; 20:376-379. http://dx.doi.org/10.1007/ s10854-008-9628-y

6. Basu S and Dutta A. Studies on $\mathrm{ZnO} / \mathrm{p}-\mathrm{Si}$ Heterojunctions Fabricated by a Modified CVD Method. Physica Status Solidi A. 1993; 136:267-272. http://dx.doi.org/10.1002/ pssa.2211360134

7. Zeng J, Kim Y and Chen Y. Photoelectrical and photovoltaic properties of $\mathrm{n}-\mathrm{ZnO} / \mathrm{p}-\mathrm{Si}$ heterojunction. Advanced Materials Research. 2012; 399-401:1477-1480.

8. Pathan HM and Lokhande CD. Deposition of metal chalcogenide thin films by successive ionic layer adsorption and reaction (SILAR) method. Bulletin of Material Science. 2004; 27:85-111. http://dx.doi.org/10.1007/BF02708491

9. Nicolau YF, Dupuy M and Brunel M. ZnS, CdS, and $\mathrm{Zn}_{1-x} \mathrm{Cd}_{x} \mathrm{~S}$ Thin Films Deposited by the Successive Ionic Layer Adsorption and Reaction Process. Journal of The
Electrochemical Society. 1990; 137:2915-2924. http://dx.doi. org/10.1149/1.2087099

10. Ristov M, Sinadinovski GJ, Grozdanov I and Mitreski M. Chemical deposition of $\mathrm{ZnO}$ films. Thin Solid Films. 1987; 149:65-71. http://dx.doi.org/10.1016/00406090(87)90249-5

11. Mondal S and Mitra P. Preparation of cadmium doped $\mathrm{ZnO}$ thin films by SILAR and their characterization. Bulletin of Material Science. 2012; 4. In press.

12. Mitra $\mathrm{P}$ and Khan K. Chemical deposition of $\mathrm{ZnO}$ films from ammonium zincate bath. Materials Chemistry and Physics. 2006; 98:279-284. http://dx.doi.org/10.1016/j. matchemphys.2005.09.042

13. Mondal S, Kanta KP and Mitra P. Preparation of Al-doped $\mathrm{ZnO}(\mathrm{AZO})$ thin film by SILAR. Jounal of Physical Sciences. 2008; 12:221-229.

14. Mondal S and Mitra P. Preparation of nanocrystalline SnS thin film by SILAR. Material Science Research India. 2008; 5:67-74.

15. Berry LG, editor. Powder Diffraction File. Philadelphia; 1960. Card no. 9. 5-0664.

16. Lee YE, Kim YJ and Kim HJ. Thickness dependence of microstructural evolution of $\mathrm{ZnO}$ films deposited by r.f. magnetron sputtering. Journal of Materials Research. 1998; 13:1260-1265. http://dx.doi.org/10.1557/ JMR.1998.0180

17. Pelleg J, Zevin LZ, Lungo S and Croitoru N. Reactivesputter-deposited TiN films on glass substrates. Thin Solid Films. 1991; 197:117-128. http://dx.doi.org/10.1016/00406090(91)90225-M

18. Seel SC, Carel R and Thompson CV. Texture maps for orientation evolution during grain growth in thin film. In: Frost HJ, Parker MA, Ross CA and Holm EA, editors. Polycrystalline Thin Films: Structures, Texture, Properties and Applications II. Materials Research Society Symposium Proceedings. 1996; 403:63.

19. Ajimsha RS, Jayaraj MK and Kukreja LM. Electrical Characteristics of $\mathrm{n}-\mathrm{ZnO} / \mathrm{p}$-Si Heterojunction Diodes Grown by Pulsed Laser Deposition at Different Oxygen Pressures. Journal of Electronic Materials. 2007; 37:770-775. http:// dx.doi.org/10.1007/s11664-007-0365-4 